\title{
The Metametaphysics of Neo-Fregeanism
}

\author{
Matti Eklund \\ matti.eklund@filosofi.uu.se
}

[published in Ricki Bliss and James Miller (eds.), The Routledge Handbook of Metametaphysics, 2020]

\section{Introduction}

Fregean approaches to branches of mathematics characteristically combine platonism (these branches of mathematics are about mind-independent abstract objects) and logicism (these branches reduce to logic). Today's neo-Fregeanism has mostly focused on arithmetic, and has centrally done so via appeal to

Hume's principle (HP): the number of Fs is identical to the number of Gs if and only if the Fs and the Gs are equinumerous,

where the Fs and the Gs are equinumerous if and only if there are exactly as many Fs as Gs. As the name suggests, neo-Fregeanism derives inspiration from Frege's ideas. The main proponents are the theorists who put this view on the contemporary map, Crispin Wright and Bob Hale, but the view also owes a lot to earlier writings by Michael Dummett.

\section{Background}

Frege's logicism is the view that arithmetic reduces to logic. Frege's own attempt at reducing arithmetic to logic famously failed. What Frege did was to devise his own logical system, and show how arithmetic could be deduced from axioms of logic within that system. Crucial here was the axiom Basic Law V, saying, roughly, that the "value-range" of one "concept" is identical to that of another just in case the concepts are coextensive. Frege's "concepts" are, roughly, properties and relations; and "value-ranges" can be thought of as extensions. Russell's paradox showed that Basic Law V rendered Frege's logic inconsistent. Frege found no suitable way of restricting or modifying Basic Law V in light of what Russell pointed out.1

Here is a way of explaining the issue. The value-range of a property can be thought of as the set of things that have the property and Frege's theory then says that for every property there is a set of exactly the things that has the property. Among all the properties there are is the property of not being a member of oneself. Frege is committed to there being a set, or value-range, of exactly the things that

1 Discovered by Russell in 1901, communicated to Frege in the letter Russell (1902). 
have this property. Call this set R. Is R a member of itself or not? Whatever we say, we land in contradiction. If it is, it isn't. If it isn't, it is.

There is another way to defend something like Frege's view on arithmetic. In Die Grundlagen der Arithmetik (1884/1950), Frege had considered another way to reduce arithmetic to logic plus definitions, relying not on Basic Law V but instead on HP. Frege himself rejected this idea because of what has come to be known as the Julius Caesar problem: HP is insufficient to show that Julius Caesar is not a number.2 But HP has other nice features. Charles Parsons (1965) showed that (in second-order logic) the Peano axioms can be derived from Hume's principle plus what uncontroversially are definitions. George Boolos (1986) showed that Frege arithmetic - the theory obtained by adding HP to second-order logic - is consistent if classical analysis is. So HP is strong enough to found arithmetic on, while the specter of inconsistency is avoided. Neo-Fregeanism can be characterized in different ways, but one core idea is to revive something much like Frege's view, but through relying on HP instead of Basic Law V.

While Parsons had done the necessary formal groundwork, and ideas about ontology congenial to neoFregeanism had been defended by Dummett, e.g. in (1973), the first systematic defense of neoFregeanism was Crispin Wright's Frege's Conception of Numbers as Objects (1983). Neo-Fregeanism has since been defended in Bob Hale's Abstract Objects (1987), and by many papers authored by Wright and Hale, separately and jointly. Many of these papers are collected in Hale and Wright's The Reason's Proper Study (2001). While neo-Fregeanism is chiefly associated with Wright and Hale, some other authors have defended views in much the same spirit.3 In Oystein Linnebo (2018), basic ideas of neo-Fregeanism, including reliance on principles similar to HP, are employed not only in philosophy of mathematics, but also in the case of some issues in the ontology of material objects. Jeffrey Sanford Russell (2017) gives an account of mereological sums using the same strategy as the neo-Fregean uses in the case of numbers. Stewart Shapiro and Geoffrey Hellman (2017) give a neoFregean account of geometrical points. Neo-Fregeanism has generated a vast literature, both literature criticizing neo-Fregean ideas, and literature exploring these ideas further.4

Neo-Fregeans seek to found arithmetic on (second-order) logic plus HP. Like Frege himself, they take number-talk to be referring talk, and the take expressions like "the number of Fs" to be singular terms purporting to refer to numbers. Notice a prima facie tension — one I will be coming back to - between

\footnotetext{
2 It is a nice question why Frege did not think that the problem does arise equally for Basic Law V: Basic Law V seems insufficient to show that Julius Caesar is not a value-range.

3 See, e.g., Cook (2009b), Linnebo (2018) and Rayo (2016).

4 See perhaps especially Fine (2002), Heck (2011), Linnebo (2018), the essays on neo-Fregeanism in Boolos (1998), the essays in Linnebo (2009), and the essays in Ebert and Rossberg (2016), in addition to other material referred to in this overview.
} 
reducing arithmetic to logic and taking number terms to be referring terms: given the latter tenet, some arithmetical truths require for their truth that there be certain objects, numbers. How can it be a matter of logic plus definitions that such-and-such objects exist? One could defend the view that arithmetic is reducible to logic plus definitions by saying that arithmetical truths don't really concern objects - the surface structure of the language we use to do arithmetic is misleading — or perhaps by saying that truths of arithmetic really should be thought to have conditional form "if the natural numbers exist, then ...".s But that is not the way of Frege and the neo-Fregeans.

My focus here will be on the platonism the neo-Fregeans defend, and on what general views on metaphysics underlie this platonism and the defense of it. Of special concern is the neo-Fregean's characteristic marriage of logicism (mathematics, or branches thereof, can be reduced to logic plus definitions) and platonism (these branches of mathematics are about mind-independent abstract objects). How can it be true both that mathematics is about mind-independent abstract objects and that it amounts to nothing more than logic plus definitions? There are other important questions about neoFregeanism and ontology. Some concern the reliance on higher-order logic, and how higher-order quantification is best understood. Some concern the above-mentioned Julius Caesar problem. But those other questions will not be the focus here.

Apparently crucial to the neo-Fregean program is the question of the status of HP. It is supposed to have the status of a definition, while being ontologically committing. Even before getting into what, in the context, it is to have the "status of a definition", the question seems pressing: how could HP pull off the feat of having both these features? The simplest suggestion is to simply advert to its being an abstraction principle: a principle of the form

$$
\S \alpha=\S \beta \text { if and only if } \alpha \sim \beta
$$

where $\alpha$ and $\beta$ are variables of some type, $\S$ is a function from what these variables range over to objects, and $\sim$ is an equivalence relation on what the variables range over.6 Another well-known and seemingly plausible abstraction principle is the direction principle,

The direction of $\mathrm{a}=$ the direction of $\mathrm{b}$ iff $\mathrm{a}$ and $\mathrm{b}$ are parallel.

Maybe there is something about abstraction principles generally that allows for the combination of being ontologically committing and being true by definition. Maybe, to prefigure a later theme, the

\footnotetext{
5 See here Field (1984).

${ }_{6}$ Characterization adapted from Linnebo (2018), p. xii.
} 
sentences flanking an instance of an abstraction principle correspond to recarvings of one and the same content, and that is what is special about abstraction principles. However, simply saying that HP has these features because of being an abstraction principle won't really do, regardless of the details. For Basic Law V is also an abstraction principle, but Basic Law V is inconsistent. One project for the neo-Fregeans is that of delineating the class of acceptable abstraction principles. The simplest suggestion would be just to appeal to consistency: an abstraction principle is acceptable if it is consistent. But Boolos (1990) showed that some consistent abstraction principles are inconsistent with each other. The general version of this problem is known as the bad company problem. HP keeps bad company - abstraction principles which should not be accepted as having the virtues the virtues that HP has according to the neo-Fregeans. How can one separate the good abstraction principles from the bad? The bad company objection to neo-Fregeanism is the objection that there is no principled way to do so.7 However, even given an extensionally satisfactory response to the bad company objection - a proposal that classifies the abstraction principles we want to accept as good and classifies the ones we don't want to accept as bad - there still remains the issue of how the good abstraction principles could pull off the trick of being analytic while still having the status of definitions.

Thus far I have spoken of Frege's, and the neo-Fregeans', project as being to the effect of reducing arithmetic to logic plus definitions. But this talk of reduction stands in need of some discussion and unpacking. It would be possible for a theorist to hold that arithmetic is "reducible to logic and definitions" but not see this as being of great importance, for example on the ground that logical truth is as philosophically problematic as arithmetical truth to begin with. A reduction of arithmetic to logic plus definitions is philosophically important if, for example, logical truths and truths by definition are assumed to have certain epistemic and/or metaphysical features - they can be known on the basis of semantic or conceptual competence alone, and they are true purely by virtue of meaning. If so then the reduction of arithmetic to logic plus definition can show that arithmetical truths have these features too. Arithmetical truths maybe seemed worrisome before; the reduction shows that they have the same features. For example, maybe logical truths and truths by definition are analytic, and the reduction shows that also arithmetical truths are analytic. The talk of analyticity only helps given certain conceptions of analyticity: ones where analytic truths are guaranteed to have certain features. For example, given an understanding of analyticity where a sentence is analytic if understanding the expressions involved and the mode of composition is sufficient for knowledge of the truth of the sentence, analyticity has epistemic significance. Showing mathematical truths to be analytic in this sense is showing them to be knowable by virtue of semantic competence alone. I will understand the neo-Fregean to intend the reduction to have philosophically significant implications.

7 See, among other things, Boolos (1990), Cook (2009a), Cook and Linnebo (2018), Linnebo (2018), Studd (2016), Weir (2003), and Wright (1999). 


\section{Platonism and logicism}

Given the above discussion we can characterize neo-Fregeanism in the philosophy of mathematics somewhat more carefully. We can see it as the conjunction of the following tenets. Platonism: there are mind-independent abstract objects. Neo-logicism: mathematics is analytic (for example in the epistemic sense characterized above). Abstraction principles: key to the justification of the first two tenets is the reliance on abstraction principles, such as HP. The idea is that abstraction principles, or some of them, are analytic, while at the same time the truth of the left-hand side of an abstraction principle is ontologically committing, to mind-independent abstract objects.

The above paragraph characterizes neo-Fregeanism as a general philosophy of mathematics. But the focus is often specifically on arithmetic; and HP is specifically in the service of a philosophy of arithmetic. One can defend neo-Fregeanism solely about arithmetic, and give a different account of other parts of mathematics. In many of Hale and Wright's writings the focus is on arithmetic. But applications of neo-Fregeanism to set theory and analysis have also been discussed.8 Note that there is at least a potential problem here. It may be thought that the philosophical problems regarding mathematics arise in similar ways for many or all branches of mathematics, in such a way that all of these branches of mathematics should receive similar philosophical treatment. Then if, for example, there are no suitable abstraction principles on which to base analysis or set theory, neo-Fregeanism fails: for it cannot then be extended to all branches of mathematics.

Sometimes Hale and Wright present neo-Fregeanism as primarily an epistemological project.9 Thus conceived, its main aim is to account for our knowledge of mathematics. However, even if the project is epistemological, it can still have distinctive ontological implications. And some aspects of it are overtly ontological, like the commitment to platonism.

Before turning to discussions in the literature of the neo-Fregean approach to ontology, it may be useful to first consider in the abstract how one can seek to make platonism and logicism compatible, and while making abstraction principles central in this project.

One could have particular views on analyticity and on knowledge such that the analyticity of mathematical claims is compatible with all sorts of metaphysical views on mathematics. Paul Boghossian (1996) introduced the celebrated distinction between epistemic and metaphysical analyticity. As Boghossian presents the distinction, a sentence is metaphysically analytic if it is true

\footnotetext{
8 See, e.g., Boolos (1986) and (1993), Hale (2000a, 2000b), Linnebo (2018), Shapiro (2000), Studd (2016), and Wright (2000). Logan $(2015,2017)$ has applied neo-Fregean ideas to category theory.

9 Wright (2016), p. 161.
} 
purely by virtue of meaning; it is epistemically analytic if one is justified in believing it purely by virtue of semantic competence. Having introduced the distinction, Boghossian argued that while no sentence can be metaphysically analytic, some sentences can still be epistemically analytic. The argument to the effect that no sentence is metaphysically analytic runs as follows. In general for a sentence $S$ to be true, the following two conditions must be satisfied: (i) $S$ means that $p$, and (ii) $p$. Since the second condition must always be satisfied, the sentence is not true in virtue of meaning alone.10

The reason Boghossian's stance is relevant in the context is that it is metaphysical analyticity that is most obviously in tension with platonism: how can ontologically committing claims be true purely by virtue of meaning? To be sure, one can also wonder how the epistemic analyticity of a sentence is compatible with its being ontologically committing. But here is a model of how this can be so: the concept's semantic value is what makes true the constitutive principles, when there is a possible semantic value that does so. The determination of semantic value can work in this way even when it is a substantive claim that there in fact is something that makes true the constitutive principles.

Against this general background, it can be suggested that HP can be epistemically but not metaphysically analytic. The idea is that even if HP it is not metaphysically analytic, it can still be epistemically analytic - and the world can be such that it is in fact true, even if laying it down as a stipulation does not itself guarantee that it is in fact true. I do not know of anyone who has actually taken this route, but it seems a reasonable route to explore.

Some other ways of rendering platonism and neo-logicism compatible are more metaphysical in nature, and involve defending the metaphysical analyticity of mathematics, or specific branches thereof. Before I turn to the specific suggestions, some remarks on Boghossian's argument against metaphysical analyticity. The argument is quick. It overlooks that one idea related to that of truth in virtue of meaning is that some propositions are vacuously true; they don't demand anything of the world.11 If sentence $\mathrm{S}$ means that $\mathrm{p}$ and the proposition that $\mathrm{p}$ is such a proposition is such $\mathrm{a}$ proposition, then condition (ii) is vacuously satisfied, and S can be said to be true by virtue of meaning alone. Needless to say, the notion of vacuous truth can itself be questioned, but that is another matter.

Given this as background, suppose that one takes number facts to be grounded in facts about equinumerosity, in such a way that HP is true. And suppose further that grounding is to be so understood that if the fact that $\mathrm{A}$ is fully grounded in the fact that $\mathrm{B}$, then the fact that $\mathrm{A}$ is nothing

\footnotetext{
10 Boghossian (1996), p. 364.

11 Boghossian only considers another response: that S's meaning that $p$ somehow makes it the case that p (1996, p. 364f).
} 
over and above the fact that $\mathrm{B}$. Then fact $\mathrm{A}$ does not require anything more of the world than that $\mathrm{B}$ obtains - even if the fact that $\mathrm{A}$ is a fact to the effect that such-and-such entities exist and fact $\mathrm{B}$ does not concern such entities. HP or its instances can then be metaphysically analytic even if the left hand side requires numbers and the right hand side does not concern such entities. They are so, if fact A's requiring nothing of the world over and above what fact $B$ requires means that the fact expressed by "A iff B" requires nothing of the world.12 While this latter claim of course can be denied, it is easy to see how it can be found attractive.

This kind of metaphysical route has been explored by some authors. Gideon Rosen (2010), Robert Schwartzkopff (2011), Tom Donaldson (2017), Linnebo (2018), and Ciro de Florio and Luca Zanetti (forthcoming) have explored what is sometimes called the Rosen-Schwartzkopff principle. In Donaldson's rough formulation:

For any properties $\mathrm{F}$ and $\mathrm{G}$, if the number of things that have the property $\mathrm{F}$ is identical to the number of things that have the property $\mathrm{G}$, then this fact is grounded by the fact that the things that have the property $\mathrm{F}$ and the things that have the property $\mathrm{G}$ can be paired one-to-one.13

While this principle is more complex, it is intended to be a grounding-theoretic counterpart of HP.

A different way to marry neo-Fregeanism and metaphysical analyticity is suggested by recent work due to Agustín Rayo (2013). Rayo's discussion is centered on an extended critical argument against what Rayo calls metaphysicalism. Rayo's metaphysicalist holds that for an atomic sentence of a given form to be true, there needs to be the right "kind of correspondence" between "the logical form of a sentence and the metaphysical structure of reality". More specifically, for an atomic sentence to be true, the singular terms and the predicate must refer to objects and a property such that these objects and this property are carved up by the world's metaphysical structure. Rayo rejects metaphysicalism. Given this rejection of metaphysicalism, Rayo thinks that there is nothing that blocks maintaining, e.g., that for the number of dinosaurs to be zero just is for there to be no dinosaurs. The thought is this. Were metaphysicalism to be true the differently structured constructions flanking the "just is" would demand different things of the world; but now we can instead say that they demand the very same thing. Given Rayo's view it can be held that for the left hand side of an instance of HP to hold just is for the right hand side to hold. This is a different route to metaphysical analyticity of the instances of

12 Needless to say, some steps here can be questioned; and there are conceptions of grounding given which the connection between grounding and "nothing over and above" does not hold.

13 Donaldson (2017), p. 775. Much of Donaldson's article is then devoted to finding the best formulation of the principle. 
HP. Again this demands that if for A to hold just is for B to hold, then the biconditional that A iff B is metaphysically analytic.

Ross Cameron (2008) holds that the neo-Fregean would be wise to relate (HP) to truth-making: more specifically, to say that "the number of Fs = the number of Gs" and "the Fs and the Gs are equinumerous" have the same truth-maker, that the Fs and the Gs are equinumerous. Given this, then again all that is demanded of the world for it to be true that the number of Fs = the number of Gs, and hence for there to be numbers, is that the Fs and the Gs are equinumerous. Again this is naturally put in terms of metaphysical analyticity. If the sentences flanking an instance of HP have the same truthmaker, then if one is true, nothing more is demanded of the world for the other to be true as well.

\section{The neo-Fregean as quietist}

Let me now start inching towards what Hale and Wright themselves have actually said about the metaontology of neo-Fregeanism . But before attending directly to what they write, let me discuss how they have been understood by commentators. The reason for waiting before introducing the stars of the show is that it is somewhat simpler to discuss Hale and Wright once we have more of the theoretical map clearly in view.

Several authors commenting on neo-Fregeans' writings have, in different ways, presented suggestions regarding the metaontology of neo-Fregeanism - regarding the stance with respect to ontological questions which underlies neo-Fregeanism. This project is to some extent one of interpretation (what do the neo-Fregeans have in mind?) and to some extent one of rational reconstruction (what is the best kind of view on ontology for someone who wishes to embrace the neo-Fregeans' theses?)

Much of the earliest commentary on neo-Fregeanism concerned other aspects of the neo-Fregean project. Some commentators focused heavily on the bad company objections and on technical aspects of the neo-Fregean program. Hale, Wright and Dummett had an important debate over whether number terms introduced by HP refer in the same sense as that in which ordinary referring terms do. 14 The more general critical discussion of the metaontology of neo-Fregeanism took off fairly late somewhat paradoxically so, since general pronouncements on the nature of ontology were more prominent in 1980s work by Wright and Hale, such as Wright (1983) and Hale (1987), than they have tended to be in later work.

14 See Dummett (1991, 1998), Hale (1994) and Wright (1998a, 1998b). 
A relatively early discussion of the metaontology of neo-Fregeanism is found in a part of Fraser MacBride's overview article (2003). In his more recent (2016), MacBride revisits the relevant theme from that article, presenting his point in terms of a supposed dilemma for the neo-Fregean:

If reality is crystalline then their view that reality contains a sufficient plenitude of objects, properties and relations arranged thus-and-so to make their periphrases for established truths true is left hostage to cosmological fortune. Whereas if reality is plastic then it becomes dubiously coherent to conceive of our ordinary, scientific and mathematical claims about a diversity of objects as being genuinely true or false of an independent reality. 15

(If reality is "crystalline" then it "consists of states of affairs - objects, properties and relations arranged thus-and-so - whose structure is fixed quite independently of language".16)

The thought is this. Either the existence of mathematical objects is mind-dependent or it is not. If it is not, then our reliance on HP seems to be on shaky ground. From where does the assurance come that there mind-independently are the objects there need to be in order for HP to be true? If, by contrast, it is mind-dependent what mathematical objects there are, this epistemological mystery may be averted, but now we have abandoned the realist view that mathematical claims are made true or false by an independent reality. And this - and perhaps this ought even to be added to the above characterization of neo-Fregeanism - is a realist view that the neo-Fregean seeks to accept.

MacBride has a suggested way out for the neo-Fregean. It is that we can deny "that there is an intelligible question to be raised" regarding "how language hooks onto reality".17 If we can deny this, then we can agree that a sentence $S$ is true "without thereby becoming embroiled in the uncomfortable consequences of having to say what makes $\mathrm{S}$ true". 18 On the view suggested, there is no perspective we "can adopt whereby language-as-a-whole can be significantly compared to something else, viz. reality". Summing up the suggestion, MacBride says,

We are no more capable of adopting such a perspective outside of language from which we can measure language against reality and pronounce upon its representational efficacy than we can step outside our own skins. Consequently there is no "ontological gap" to be bridged between what is truly said and what the world is like.19

15 MacBride (2016), p. 96.

16 MacBride (2016), p. 94.

17 MacBride (2016), p. 97.

18 MacBride (2016), p. 97.

19 MacBride (2016), p. 97. 
I see two substantive problems with MacBride's discussion. One is that many key formulations are epistemic rather than metaphysical. For example, in the above, the material before the "consequently" is only epistemic: it only comments on our limitations as knowers, and on what we can measure against what. That is compatible with all sorts of metaphysical views. But what follows the "consequently" is about metaphysics and not epistemology. What is the connection between the epistemic assumptions and the metaphysical conclusions supposed to be? Second, more importantly, note that MacBride describes the ontological gap as between what is "truly said" and what the world is like. MacBride describes quietism as a distinctive and radical doctrine but there is a sense in which, on most views, there is no ontological gap of the kind described: if it is truly said that $p$, then here's one way the world is like: the world is such that p. I am not merely harping on a bad formulation. Just below, MacBride speaks of falling prey to the temptation " $[t]$ o demand supernumerary assurance of word-world co-operation before being willing to acknowledge the existence of objects that correspond to the occurrence of syntactically singular expressions in true sentences".20 Again the truth of the sentences is presupposed, and the question concerns what the truth of the sentence entails. This may be thought innocuous: if the truth of $p$ entails that $q$, then a requirement for it to be the case that $p$ is that q. But it is a problem that the truth of the sentences is just assumed, since many would find it exceedingly plausible that given that the sentences are indeed true, then the corresponding objects exist. It seems more reasonable to seriously question whether the relevant sentences are true.

MacBride does talk about submitting "to the norms of our discourse", but the connection between this and what his quietism officially concerns remains unexplored.21 One reason why I bring up this issue regarding MacBride is that we will see similar issues arise regarding Wright and Hale.

\section{Easy existence}

Two other proposed interpretations of the metaontology of neo-Fregeanism instead take the neoFregeans to rely on an assumption to the effect that existence is easy. Speaking intuitively: the worry that numbers may simply fail to exist is due to thinking of existence as a significant achievement, but existence is in fact easily had. But this way of thinking is mistaken. The point is usefully explained in terms of MacBride's dilemma. What if facts about what objects there exist are mind-independent - in accordance with the second horn - but existence is easily had? If so, then the worry that, say, numbers may fail to exist can anyway be set aside as misguided.

${ }^{20}$ MacBride (2016), p. 97

${ }_{21}$ MacBride (2016), p. 106. Note that the talk of submitting to the norms of our discourse is again epistemic, as it seems to address the issue when we should accept the sentences as true. That issue is different from the issue of the conditions under which the sentences are true. The relevant metaphysical view would be that the sentences are true exactly when they are true according to the norms of our discourse. Another view still would profess agnosticism about the metaphysics, and simply say that the best we can do is to submit to the norms of our discourse. 
One of these two easiness interpretations is the maximalist interpretation defended by myself (2006, 2016) and by Katherine Hawley (2007).22 Maximalism is here the view that anything which satisfies already very weak conditions also does exist. Maximalism is itself just a view on what exists. It is not itself a metaontological view. But the idea behind the maximalist understanding of neo-Fregeanism is that there is some metaontological view - some view on the nature of existence - that neo-Fregeanism relies on, and this metaontological view has maximalism as a consequence.23 For example, I argue in my (2006) that Wright holds reference to be secondary to truth in a particular way and that is what drives the whole thing. In arguing what I do I compare arguments given in a different context in Wright (1992). Given a metaontological view of the kind described, there is a guarantee that so long as some newly introduced terms satisfy some very weak conditions - in the case of pure abstracta, something like that the stipulations introducing them are coherent - those terms refer.

The other easiness interpretation, due to Sider (2007), is the quantifier variance interpretation. The doctrine of quantifier variance - introduced, under that name, by Eli Hirsch is, at a first stab, the doctrine that there are different possible existential quantifier meanings, and no one quantifier meaning is privileged over all the others. 24 If the neo-Fregean relies on quantifier variance, then she can say that what guarantees the success of the stipulation of an abstraction principle (satisfying weak conditions) is that there will be some meaning or other for the existential quantifier such that when the quantifier expression has that meaning, the abstraction principle is true. The guarantee isn't that the newly introduced terms refer to entities that exist in the ordinary sense of "exists" but that the terms refer to entities in some sense of "exists", and what the stipulation of HP effects is that we come to use "exists" in such a way that the sentence employed to state HP comes out true.

Neither easiness interpretation immediately addresses epistemological concerns. Under both interpretations, the metaontological claim emphasized must be supplemented by other assumptions in order to properly explain knowledge of the existence of mathematical objects.

\section{Early Wright and Hale}

Having discussed the metaontology of neo-Fregeanism in general terms and having discussed commentators, let me now finally turn to what Wright and Hale themselves have said about the matter.

\footnotetext{
22 Some qualifications are needed. Hawley only compares the maximalist interpretation with the quantifier variance interpretation (see just below) and argues that the former is preferable. And in my (2006) I only took myself to be discussing a strand of thought in earlier neo-Fregean writings.

${ }_{23}$ Compare the liberal ontological views defended in Schiffer (2003) (regarding abstracta) and Thomasson (2015) (more generally).

24 See the essays collected in Hirsch (2011). In Eklund (forthcoming), I discuss and compare some different views that have been discussed under the heading quantifier variance.
} 
They have said somewhat different things over the years. I will discuss some different themes that have come up.

Much of Wright (1983) was devoted to discussion of the notion of an object which his neoFregeanism is said to rely upon. The focus is on Frege's context principle, and on the syntactic priority thesis - "the thesis of the priority of syntactic over ontological categories" 25 - which Wright says follows from it. What has come to be known as the context principle receives some different formulations in Frege's Grundlagen (1884), but in one famous formulation, it is the principle that "it is only in the context of a sentence that words have any meaning".26 Wright spells out the syntactic priority thesis as follows:

According to this thesis, the question of whether a particular expression is a candidate to refer to an object is entirely a matter of the sort of syntactic role which it plays on whole sentences. If it plays that sort of role, then the truth of appropriate sentences in which it so features will be sufficient to confer on it an objectual reference; and questions concerning the character of its reference should then be addressed by philosophical reflection on the truth-conditions of sentences of the appropriate kind.27

Needless to say, it is not immediate or uncontroversial that the syntactic priority thesis follows from, or even is very closely related to, the context principle as intended by Frege.

Note that it is apparently fully consistent with the syntactic priority thesis so understood to deny that number terms refer - even if they syntactically are singular terms. What follows from the syntactic priority thesis is only that given that they syntactically are singular terms then they are candidates to refer to objects, and so if appropriate sentences containing them are true there are objects to which they refer. But nothing is said which addresses whether any appropriate sentences are true, or how to determine that.

What I am complaining about is the same sort of thing I earlier complained about regarding MacBride. The truth of the relevant sentences is just taken for granted; what is problematized is only what follows from the truth of these sentences.

Here is one more illustration. Hale (1987) lays out what he calls the "Fregean argument" as follows:

25 Wright (1983), p. 51.

26 Frege (1884), §53.

27 Wright (1983), p. 51f. There are very similar passages found in earlier writings by Dummett, see e.g. his

(1956), p. 40f. 
(1) If a range of expressions function as singular terms in true statements, then there are objects denoted by expressions belonging to that range

(2) Numerals and many other numerical expressions besides, do so function in many true statements (of both pure and applied mathematics)

Hence

(3) There exist objects denoted by these numerical expressions (i.e. there are numbers) 28

Hale then launches straight into a thorough discussion of the criteria for being a singular term, and the case that can be made for thinking that many numerical expressions. He discusses a number of objections to the platonism he defends, including Benacerraf's arguments concerning mathematical knowledge, and concerning indeterminacy.29 But he never pauses on what positive case can be made for thinking that the relevant kinds of statements are true.

In a somewhat later piece, the introduction to their joint (2001), Hale and Wright describe neo-Fregean platonism as relying on two ideas. One is that objects just are whatever singular terms refer to. The other is that "no more is to be required, in order for there to be a strong prima-facie case that a class of apparent singular terms have reference, than that they occur in true statements free of all epistemic, modal, quotational, and other forms of vocabulary standardly recognized to compromise straightforward referential function". 30 Striking, again, is that they do not pause on the question of the truth of the statements.

All this said, I think it is clear, intuitively, what picture Wright and Hale are operating with. If the category of object is explained via that of the category of (referring) singular term, then there is nothing that stands in the way of the truth-conditions of appropriate sentences containing singular terms purporting to refer to Ks being the same as the truth-conditions of sentences without such Kterms. For given some sentences of the latter kind one can introduce sentences with what syntactically are singular terms with the stipulation that the newly introduced sentences are to have the same truthconditions as the old ones; and if the category of object is simply understood in terms of that of singular term, then there is no real possibility that such a stipulation will fail simply on the ground that the world happens to fail to contain the objects in question. But it still remains that the syntactic priority thesis itself does not say anything about this. No general principle has been produced which would justify this broad claim.

\footnotetext{
28 Hale (1987), p. 11.

29 See Benacerraf (1965) and (1970).

30 Hale and Wright (2001), p. 8.
} 
It is natural to think that in the background of Hale and Wright's neo-Fregeanism lies something like Rayo's anti-metaphysicalism and not what Wright calls the syntactic priority thesis. If metaphysicalism is rejected, then the path lies open to reasonably holding that for it to be the case that the number of Fs = the number of Gs just is for it to be the case that the concepts $F$ and $G$ are equinumerous. Rejecting metaphysicalism relates to what truth demands, by saying something about what truth does not demand: the truth of a sentence does not require there to be a structural correspondence between the sentence and reality.

Later in (1983), Wright turns directly to HP and lays out the impressive formal case that can be made for reliance on HP: in second-order logic, all of second-order arithmetic follows from HP plus what uncontroversially are definitions, and the system is equiconsistent with ordinary second-order Peano arithmetic. Moreover, regardless of what to say about theoretical matters, HP does have an air of being a definition. There is what may be called a possible "particularist" line - particularist in the sense that it does not seek to motivate HP by appeal to general considerations - which focuses on HP because it has these good-making features but which eschews any attempt at a general theoretical scaffolding. Another possible reason why Wright and Hale do not pause on the truth of the relevant mathematical sentences might be thought to be that they can justifiably simply rely on this as an assumption. Given both the success of mathematics and what common sense suggests, there is prima facie reason to take these sentences to be true. Then so long as arguments to the contrary can be rebutted we can indeed reasonably take these sentences to be true. No more direct argument for their truth is required. But for what it is worth, Wright and Hale do seem to wish to provide more by way of theoretical scaffolding than a thoroughgoing particularism would allow; and they do seem to seek to provide direct arguments for the claim that some ontologically committing mathematical claims are true.

\section{Content recarving and implicit definition}

In some of their writings, the neo-Fregeans relied on a notion of content recarving. 31 The same content can be recarved in different ways, and this is what is going on with acceptable abstraction principles: the sentences flanking an instance of such a principle in some sense have the same content, only carved up in different ways. The question is what criterion of individuation of content should be employed here. If the criterion is very coarse-grained (e.g. metaphysically necessary equivalence), then the claim of sameness of content is plausible, but it is correspondingly implausible that sameness of content of two sentences implies that the sentences thereby have the same epistemic and metaphysical status. If the criterion is more fine-grained (e.g., the content of a sentence is the structured proposition it expresses, where propositional structure is isomorphic to linguistic structure), it is plausible that sentences with the same content thereby have the same epistemic and metaphysical

31 See e.g. Hale (1997) and Wright (1997). 
status, but it is implausible that sentences flanking an instance of HP indeed have the same content. Linnebo (2018) calls this the Goldilocks problem: "Is there a notion of content with granularity that is just right, neither too coarse nor too fine?". 32

The neo-Fregeans' attempts to solve the Goldilocks problem have met with serious criticism.33 Maybe as a result, the neo-Fregeans have more recently tended to emphasize content recarving less - although the notion is again appealed to in Hale and Wright (2009b), which I will get to in the next section. What Hale and Wright have turned to instead is implicit definition, and criteria for something to be an implicit definition.

In his (2009), John MacFarlane asks the question: what good reason might the neo-Fregean have for focusing on abstraction principles rather than directly on the axioms of Peano arithmetic? He focuses specifically on the theory of implicit definition in Hale and Wright (2000). His answer is negative: the neo-Fregean has no good reason for focusing on abstraction principles. If HP satisfies their criteria for being an acceptable implicit definition, then so do the Peano axioms. In their (2009a), Hale and Wright attempt to reply to MacFarlane.

Whether or not MacFarlane's question is an embarrassing one for Hale and Wright it can certainly seem embarrassing for the offered interpretations. Quietism: Couldn't the neo-Fregean equally well lay down the Peano axioms by stipulation, and answer doubts about their truth by appeal to quietism? Maximalism: if existence is easy in the way the maximalist interpretation holds, then it is also easy for the Peano axioms to come out true. Quantifier variance: if stipulating that the sentence used to state HP comes out true manages to affect the meaning of the existential quantifier in such a way that this sentence comes out true, why can't we achieve the same by stipulating that the sentences used to express the Peano axioms come out true? MacFarlane's question arises also for the suggestion that the neo-Fregean simply appeal to Boghossian's distinction between different kinds of analyticity: if HP can be epistemically analytic despite making a substantive claim about the world, can't this go also for the Peano axioms? The ideas that might fare better are the ones I introduced in connection with metaphysical analyticity. Focus first on the Rosen-Schwartzkopff idea: HP can be used as an account of wherein the number facts may be grounded (equinumerosity relations between concepts), but the Peano axioms do not in the same way suggest a similarly attractive story about grounding. Similarly, Rayo's strategy relies on “just is"-statements, and while HP can obviously be recast as a "just is"statement, there appears to be no natural way of so using the axioms of PA. Turning to Cameron, the

32 Linnebo (2018), p. 78.

33 For Hale's proposal, see Hale (1997) (and the postscript to it in Hale and Wright (2001)). For critical discussion, see e.g. Potter and Smiley (2001) and (2002), Fine (2002), pp. 39-41, and chapter 4 of Linnebo (2018). 
point he makes is that the sentences flanking an instance of HP can have the same truthmaker, and there is no straightforward way of developing that idea in the case of the axioms of PA. All this said, MacFarlane brings up suggestions regarding how the PA axioms could be relevantly analogous here too. If one can stipulate HP, can one not equally well stipulate

$$
\forall \mathrm{x}(\mathrm{x}=\mathrm{x}) \equiv \mathrm{PA} ? 34
$$

Elaborating on what MacFarlane says, couldn't one say that the PA axioms are ungrounded, zerogrounded (grounded but not in anything), or grounded in The True? Couldn't one say that for there to be numbers just is for The True to obtain? Couldn't one say that the PA axioms don't need truthmakers, or have the same truthmaker as The True?

\section{The metaontology of abstraction}

A more recent article by Hale and Wright, their (2009b), focuses on metaontology, and contains criticisms of the maximalist and quantifier variance interpretations, as well as Hale and Wright's own statement of their positive view. The following passage sums up their main message:

The kind of justification which we acknowledge is called for is precisely justification for the thought that no such [metaphysical] collateral assistance is necessary. There is no hostage to redeem. A (good) abstraction itself has the resources to close off the alleged (epistemic metaphysical) possibility. The justification needed is to enable — clear the obstacles away fromthe recognition that the truth of the right-hand side of an instance of a good abstraction is conceptually sufficient for the truth of the left. There is no gap for metaphysics to plug, and in that sense no 'metaontology' to supply. This view of the matter is of course implicit in the very metaphor of content recarving. 35

Hale and Wright understand the friends of the maximalist and quantifier variance interpretations to take the neo-Fregean claims to stand in need of metaphysical "collateral assistance": to take the neoFregean to need to rely on some underlying metaphysical assumptions. 36 They reject this supposed demand, as seems reasonable. Whatever the underlying metaphysical assumptions may be, one can ask what justifies them in turn. However, seen as a criticism of the two other interpretations offered, this seems unfair. What the interpretations fasten on is just that the neo-Fregean defense of HP does not

34 MacFarlane (2009), p. 455.

35 Hale and Wright (2009b), p. 193. I mentioned earlier that in later writings, Wright and Hale have tended to focus less on content recarving - but note that content recarving is prominently mentioned here.

36 There is no discussion of MacBride's quietist interpretation in Hale and Wright (2009b). 
take place in a theoretical vacuum, but the neo-Fregeans adduce reasons for thinking HP has the features ascribed to it - and these reasons adduced seem like they generalize beyond the case at hand.

More interestingly, Wright and Hale describe their own positive account. Central to their discussion is the distinction between so-called sparse and abundant conceptions of properties. They take the abundant conception as a model for what they want to say about objects:

On one way of taking it, the relevant notion of genuine property is akin to that in play when we conceive it as a nontrivial question whether any pair of things which both exemplify a certain set of surface qualities - think, for example, of a list of the reference-fixers for 'gold' given in a way independent of any understanding of that term or an equivalent - have a property in common. When the question is so conceived, the answer may be unobvious and negative... However this conception stands in contrast with that of the more "abundant" theorist, for whom the good standing, in that sense, of a predicate is already trivially sufficient to ensure the existence of an associated property, a (perhaps complex) way of being which the predicate serves to express. For a theorist of the latter spirit, predicate sense will suffice, more or less, for predicate reference. 37

in general terms, the abstractionist metaphysics of abstract objects, and of reference to themsometimes called minimalism - stands to the conception of the matter that underwrites the reference-fixing model as an abundant conception of properties stands to a sparse one.38

They discuss the obvious disanalogy that on the abundant conception of properties, any predicate with a sense also ascribes a property whereas the analogous claim about objects seems absurd.

On the abundant view of properties, predicate sense suffices for reference. But it is not the abstractionist view of singular terms that sense suffices for reference- the view is that the truth of atomic contexts suffices for reference. However everyone agrees with that. The controversial point is what it takes to be in position reasonably to take such contexts to be true. The point of analogy with the abundant view is that this is not, by minimalism, conceived as a matter of hitting off, Locke-style, some 'further' range of objects. We can perfect the analogy if we consider not simple abundance but the view that results from a marriage of abundance with Aristotelianism. Now the possession of sense by a predicate no longer suffices, more or less, for reference. There is the additional requirement that the predicate be true of something, and hence that some atomic statement in which it occurs predicatively is true. 39

\footnotetext{
37 Hale and Wright (2009b), p. $197 \mathrm{f}$.

38 Hale and Wright (2009b), p. 207.

39 Hale and Wright (2009b), p. 208.
} 
But what they say here is problematic, and the problems are of a kind we have seen before. They say first that the view is not simply that the truth of atomic contexts suffices for reference - "everyone agrees with that".40 The more central issue is: what does it take for atomic contexts to be true? Their only answer to this is negative: it is not a matter of "hitting off...some 'further' range of objects". This may not be fully clear - but more importantly, it does not address what exactly is needed. This is the same thing I raised complaints about earlier, when discussing early Wright and Hale. My complaint there was that the issue of truth is not explicitly addressed. Here the issue of truth is explicitly addressed, and it is at least clear that Hale and Wright take themselves to have a general point about what truth demands. However, their only remark is negative.

\section{Concluding remarks}

I have here provided an overview of issues regarding the metaontology of neo-Fregeanism. I have discussed various things Hale and Wright have said, various interpretations of their views found in the literature, as well as some other possible views the neo-Fregean might in principle appeal to.

As mentioned, I have myself elsewhere $(2006,2016)$ defended a particular view on what the neoFregeans commit to, the maximalist interpretation. I have not tried to again make the case here for this view.

I have also not tried to issue a general verdict on the neo-Fregean ideas, or even on those ideas that have to do with metaontology specifically. Instead I have merely tried to provide a helpful map of the territory. For what it is worth, I find the neo-Fregean project extremely attractive. But my aim here has not been to provide a brief for neo-Fregeanism, but to discuss different questions pertaining to the metaontological issues that come up in connection with the view.

\section{REFERENCES}

Benacerraf, Paul: 1965, "What Numbers Could Not Be", Philosophical Review 74: 47-73.

Benacerraf, Paul: 1970, "Mathematical Truth”, Journal of Philosophy 70: 661-79.

Boghossian, Paul: 1996, “Analyticity Reconsidered”, Noûs 30: 331-68.

Boolos, George: 1986, “Saving Frege From Contradiction”, Proceedings of the Aristotelian Society

87: 137-151.Reprinted in Boolos (1998).

40 There is more controversy here than Wright and Hale let on. What Wright and Hale think is that if " $F(a)$ " is true, then "a" refers and hence a exists. So from the truth of atomic contexts they think it can be concluded that there exists something which the singular term or terms in the sentence refer to. This is something some theorists would deny. 
Boolos, George: 1990, “The Standard of Equality of Numbers", in Boolos (ed.) Meaning and Method: Essays in Honor of Hilary Putnam, Cambridge University Press, Cambridge, pp. 261-77. Reprinted in Boolos (1998).

Boolos, George: 1993, "Whence the Contradiction?", Proceedings of the Aristotelian Society Suppl. Vol. 67: 213-34. Reprinted in Boolos (1998).

Boolos, George: 1998, Logic, Logic and Logic, Harvard University Press, Cambridge, Massachusetts. Cameron, Ross: 2008, "Truthmakers and Ontological Commitment: or How to Deal With Complex Objects and Mathematical Ontology Without Getting Into Trouble”, Philosophical Studies 140:118.

Cook, Roy: 2009a, "Hume’s Big Brother: Counting Concepts and the Bad Company Objection", Synthese 170: 349-69.

Cook, Roy: 2009b, "New Waves on an Old Beach: Fregean Philosophy of Mathematics Today", in Oystein Linnebo and Otavio Bueno (eds.), New Waves in Philosophy of Mathematics, Palgrave Macmillan, London, pp. 13-34.

Cook, Roy T. and Oystein Linnebo: 2018, "Cardinality and Acceptable Abstraction”, Notre Dame Journal of Formal Logic 59: 61-74.

De Florio, Ciro and Luca Zanetti: forthcoming, "On the Schwartzkopff-Rosen Principle", Philosophia. Donaldson, Tom: 2017, "The (Metaphysical) Foundations of Arithmetic", Noûs 51: 775-801.

Dummett, Michael: 1956, "Nominalism”, Philosophical Review 65: 491-505.

Dummett, Michael: 1973, Frege: Philosophy of Language, Duckworth, London.

Dummett. Michael: 1991, Frege: Philosophy of Mathematics, Duckworth, London.

Dummett, Michael: 1998, “Neo-Fregeans: In Bad Company?”, in Schirn (1998), pp. 369-88.

Ebert, Philip and Marcus Rossberg (eds.): 2016, Abstractionism, Oxford University Press, Oxford.

Eklund, Matti: 2006, "Neo-Fregean Ontology", Philosophical Perspectives 20: 95-121.

Eklund, Matti: 2016, "Hale and Wright on the Metaontology of Neo-Fregeanism", in Ebert and Rossberg (2016), pp. 79-93.

Eklund, Matti: forthcoming, "Collapse and the Varieties of Quantifier Variance", in James Miller (ed.), The Language of Ontology, Oxford University Press, Oxford.

Field, Hartry: 1984, "Critical Notice of Crispin Wright's Frege's Conception of Numbers as Objects", Canadian Journal of Philosophy 14: 637-62.

Fine, Kit: 2002, The Limits of Abstraction, Oxford University Press, Oxford.

Frege, Gottlob: 1884, Die Grundlagen der Arithmetik, Wilhelm Koebner, Breslau. English translation by J.L. Austin, The Foundations of Arithmetic, Blackwell, Oxford, 1950.

Hale, Bob: 1987, Abstract Objects, Blackwell, Oxford.

Hale, Bob: 1994, "Dummett's Critique of Wright's Attempt to Resuscitate Frege", Philosophia Mathematica 2: 122-47. Reprinted in Hale and Wright (2001). 
Hale, Bob: 1997, “Grundlagen §64”, Proceedings of the Aristotelian Society 97: 243-61. Reprinted with a postscript in Hale and Wright (2001).

Hale, Bob: 2000, "Reals by Abstraction”, Philosophia Mathematica 8: 100-123. Reprinted in Hale and Wright (2001).

Hale, Bob: 2000, “Abstraction and Set Theory”, Notre Dame Journal of Formal Logic 41: 379-98.

Hale, Bob and Crispin Wright: 2000, "Implicit Definition and the A Priori", in Paul Boghossian and Christopher Peacocke (eds.), New Essays on the A Priori, Oxford University Press, Oxford, pp. 286-319 Reprinted in Hale and Wright (2001).

Hale, Bob and Crispin Wright: 2001, The Reason's Proper Study, Oxford University Press, Oxford. Hale, Bob and Crispin Wright: 2009a, "Focus Restored: Comments on John MacFarlane", Synthese 170: 457-82.

Hale, Bob and Crispin Wright: 2009b, “The Metaontology of Abstraction”, in David Chalmers, David Manley and Ryan Wasserman (eds.), Metametaphysics, Oxford University Press, Oxford, pp. 178212.

Hawley, Katherine: 2007, "Neo-Fregeanism and Quantifier Variance”, Proceedings of the Aristotelian Society Suppl. Vol. 81: 233-49.

Heck, Richard G.: 2011, Frege's Theorem, Oxford University Press, Oxford.

Linnebo, Oystein (ed.): 2009, Special issue on the bad company objection, Synthese 170: 321-482.

Linnebo, Oystein: 2018, Thin Objects, Oxford University Press, Oxford.

Logan, Shay Allen: 2015, “Abstractionist Categories of Categories", Review of Symbolic Logic 8: 70521.

Logan, Shay Allen: 2017, "Categories for the Neologicist", Philosophica Mathematica 25: 26-44.

MacBride, Fraser: 2003 "Speaking With Shadows: A Study of Neo-Logicism", British Journal for the Philosophy of Science 54:103-63.

MacBride, Fraser: 2016, "NeoFregean Metaontology", in Ebert and Rossberg (2016), pp. 94-112.

MacFarlane, John: 2009, “Double Vision: Two Questions About the Neo-Fregean Program”, Synthese 170: 443-56.

Parsons, Charles: 1965, "Frege's Theory of Number", in Max Black (ed.), Philosophy in America, Cornell University Press, Ithaca, pp. 180-203.

Potter, Michael and Timothy Smiley: 2001, “Abstraction by Recarving”, Proceedings of the Aristotelian Society 101: 327-38.

Potter, Michael and Timothy Smiley: 2002, "Recarving Content: Hale's Final Proposal”, Proceedings of the Aristotelian Society 102: 301-4.

Rayo, Agustín: 2013, The Construction of Logical Space, Oxford University Press, Oxford.

Rayo, Agustín: 2016, “Neo-Fregeanism Reconsidered”, in Ebert and Rossberg (2016), pp. 203-21. 
Rosen, Gideon: 2010, “Metaphysical Dependence: Grounding and Reduction”, in Bob Hale and Aviv Hoffmann (eds.), Modality: Metaphysics, Logic, and Epistemology, Oxford University Press, Oxford, pp. 109-136.

Russell, Bertrand: 1902, “Letter to Frege”, in Jean van Heijenoort (ed.), From Frege to Gödel, Harvard University Press, Cambridge, Massachusetts, 1967, pp. 124-125.

Russell, Jeffrey Sanford: 2017, “Composition as Abstraction”, Journal of Philosophy 114: 453-70.

Schirn, Matthias (ed.): 1998, Philosophy of Mathematics Today, Clarendon Press, Oxford.

Schwartzkopff, Robert: 2011, "Numbers as Ontologically Dependent Objects-Hume's Principle Revisited", Grazer Philosophische Studien 82: 353-73.

Schiffer, Stephen: 2003, The Things We Mean, Oxford University Press, Oxford.

Shapiro, Stewart: 2000, "Frege Meets Dedekind: A Neologicist Treatment of Real Analysis", Notre Dame Journal of Formal Logic 41: 335-64.

Shapiro, Stewart and Geoffrey Hellman: 2017, "Frege Meets Aristotle: Points as Abstracts", Philosophia Mathematica 25: 73-90.

Sider, Theodore: 2007, "Neo-Fregeanism and Quantifier Variance", Proceedings of the Aristotelian Society Suppl. Vol. 81: 201-32.

Studd, James: 2016, “Abstraction Reconceived”, British Journal for the Philosophy of Science 67: 579-615.

Thomasson, Amie: 2015, Ontology Made Easy, Oxford University Press, Oxford.

Weir, Alan: 2003, "Neo-Fregeanism: An Embarrassment of Riches", Notre Dame Journal of Formal Logic 44: 13-48.

Wright, Crispin: 1983, Frege's Conception of Numbers as Objects, Aberdeen University Press, Aberdeen.

Wright, Crispin: 1992, Truth and Objectivity, Harvard University Press, Cambridge, Massachusetts.

Wright, Crispin: 1997, “On the Philosophical Significance of Frege's Theorem”, in Richard Heck (ed.), Language, Thought, and Logic: Essays in Honour of Michael Dummett, Oxford University Press, Oxford, pp. 201-44. Reprinted in Hale and Wright (2001).

Wright, Crispin: 1998a, “On the Harmless Impredicativity of N= (Hume's Principle)”, in Schirn (1998), pp. 339-68. Reprinted in Hale and Wright (2001).

Wright, Crispin: 1998b, "Response to Dummett”, in Schirn (1998), pp. 389-405. Reprinted in Hale and Wright (2001).

Wright, Crispin: 1999, “Is Hume’s Principle Analytic?”, Notre Dame Journal of Formal Logic 40: 630. Reprinted in Hale and Wright (2001).

Wright, Crispin: 2000, "Neo-Fregean Foundations for Analysis: Some Reflections”, Notre Dame Journal of Formal Logic 41: 317-34.

Wright, Crispin: 2016, “Abstraction and Epistemic Entitlement”, in Ebert and Rossberg (2016), pp. $161-85$ 